\title{
Understanding Barriers to Student Success: What Students Have to Say
}

\author{
Elizabeth A. Kuley, Sean Maw, and Terry Fonstad \\ University of Saskatchewan \\ liz.kuley@usask.ca
}

\begin{abstract}
This paper focuses on feedback received from a set of qualitative questions that were administered to undergraduate students in the College of Engineering at the University of Saskatchewan, as part of a larger mixed methods study. The larger study aims to identify what characteristics, if any, can predict or are related to student success; The "start-stop-continue" method was utilized to assess student perceptions about their success in the college as a whole. The students were asked: Are there any specific things that you can think of that act/acted as barriers to your success in engineering (stop)? What could the college do/change to make first year more successful for engineering students (start)? Is there anything in your engineering degree so far that you feel is done well and helps students succeed (continue)? Students identified the quality of instruction early in their program as well as adjustment to college workloads and self-directed learning as the most significant barriers to student success.
\end{abstract}

Keywords: retention; first year; student success; stopstart-continue; formative feedback

\section{INTRODUCTION}

The University of Saskatchewan (U of S) College of Engineering (the College), similar to many engineering colleges in Canada, is taking steps to improve the retention of undergraduate students, enhance student experience, and further student success. To this end, a systematic review of existing literature was completed and presented at CEEA 2015, which identified factors that have been found to consistently interact with retention [4]: student level factors (academic achievement in high school, learning style, intrinsic motivation and attitude, self-efficacy, demographics, and resilience), instructor level factors (engagement from faculty, professional role modeling), and college level factors (institutional climate, curriculum, mentorship, peer influence and sense of belonging). In an effort to identify which of these factors impact student success and/or retention at the $\mathrm{U}$ of $\mathrm{S}$, a mixed methods study was developed which included: a focus group discussion with students who excelled in their first year of engineering, individual interviews with seven students that struggled academically in their first year, a quantitative survey deployed to all undergraduate students $(\mathrm{n}=365)$, and the analysis of historical student data spanning ten years, from 2005 to $2015(n=4680)$.

This paper discusses the qualitative portion of a 91item survey that was deployed to 1700 undergraduate students in November of 2015. The response rate for this survey was approximately $21.5 \% ; 40 \%$ of the respondents were first year students (representing approximately 30\% of first year students), $19.5 \%$ second year students, $23 \%$ third year students, and $17.5 \%$ fourth year or higher (representing approximately $18 \%$ of upper year students). The respondents represented each undergraduate engineering discipline offered at the University of Saskatchewan as represented in Figure 1.

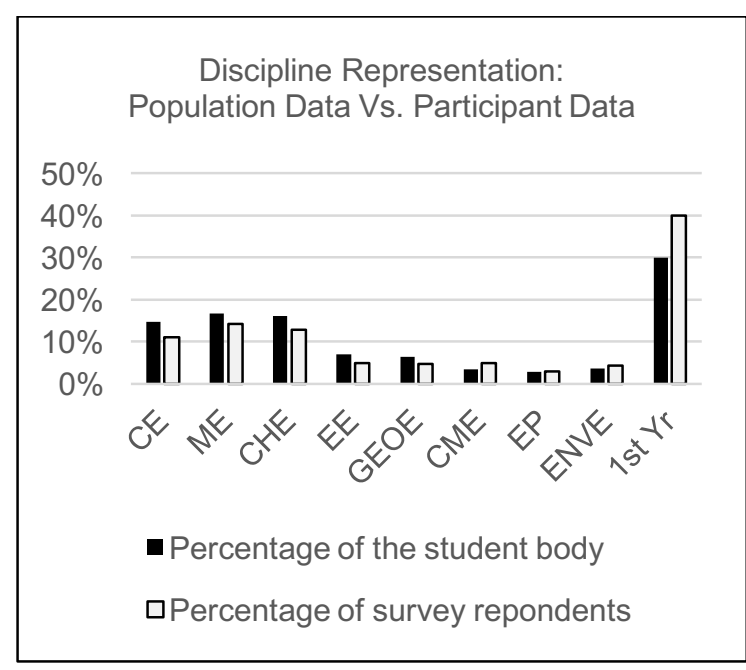

Figure 1: Distribution of respondents 
The participants included $27 \%$ female and $73 \%$ male students (compared to $19 \%$ female students in the undergraduate population), $3 \%$ self-declared aboriginal students (compared to $3.5 \%$ in the total undergraduate population), and $7 \%$ international students (compared to $13.5 \%$ in the total undergraduate population).

The qualitative portion of this survey was designed using the Stop-Start-Continue feedback technique as a framework which aims to identify, in a broad sense, what you should stop doing, start doing, and continue doing [3]. This method is used to encourage constructive qualitative feedback that is of greater depth and usefulness [2] than less structured feedback approaches. In this application, the Stop-Start-Continue method was used to identify, in relation to student success, the following: barriers that students feel need to be addressed, ideas that students have to improve the College in whatever way they felt most appropriate (culture, curriculum, etc.), and processes or programming that students feel are done well and should be continued.

Though the Stop-Start-Continue method is usually used as an evaluation tool by instructors for their courses, we saw value in using it to generate formative feedback for the College. The results of each question are discussed below. It should be noted that these questions were answered by students and the data is thus a representation of student perceptions.

\section{STOP}

In order to identify the processes, facilities, and people that students feel act as barriers to their success, i.e. what we should "stop" doing, we asked them to identify if there was anything specific that came to mind when they thought of potential barriers to their success in engineering. After coding 180 meaningful answers and grouping them into similar themes, we found that the students' answers could be funneled further into the categories that emerged from the literature review [4]: student level, instructor level, and college level These categories were adapted from what Robert Marzano calls the three levels of factors that influence elementary and high school effectiveness [5].

There were approximately a third of the responses related to each of the three levels, and an additional $9 \%$ of participants indicated that they did not have, or could not think of any barriers. The following sections describe the themes that emerged from the data, within the student, instructor, and college levels:

\subsection{Student Level}

Student level factors include those that are individual to a student, and though these factors can be influenced by instructor and college level intervention, they are primarily related to individual learners. Several themes emerged that had to do with barriers that currently exist for students.

One theme was that the engineering program as it is currently laid out seemed very inflexible $(n=17 / 180)$, and students who have additional responsibilities find the program more difficult. It should be noted that many students have additional family/personal circumstances that require their time, and/or financial barriers that make it necessary for them to work. Without flexibility being explicitly discussed (being shown how to push their program to 5 or 6 years instead of 4 , for example), they may feel overwhelmed and unsupported. Indeed, those students may not enroll in engineering in the first place; thinking that engineering is not a possibility for them.

The theme of inflexibility came up again in terms of work/life balance, in that students found it difficult to manage their program work load alongside other activities, such as trying to stay fit, maintaining friendships, trying to adjust to the changes that come with starting university, leaving home, or living in a new city. Students felt that they could not achieve a good work/life balance and still get good grades - the classic engineering catch phrase, "sleep, friends, grades... choose two," reinforces this idea.

Students also identified that being academically unprepared is a barrier that exists for some $(n=15 / 180)$. The high school courses offered to students and their quality differ from region to region, even within the same province. While some students have access to high quality AP calculus, some do not. When instructors assume that students have knowledge from high school that some students do not, those students are automatically at a disadvantage.

Many students are not used to or ready for the significant jump in workload from high school to university. Engineering students are often the best and brightest students in their high school and many have not been challenged up until they enroll in the engineering program. Being mentally and emotionally unprepared for the transition into university was identified by participants $(n=27 / 180)$ as a barrier to their success. Poor study habits and lack of motivation were noted, as were high levels of stress and anxiety. 


\subsection{Instructor Level}

Concerns about course instruction in engineering programs came up in two ways, one relating to the quality of instruction $(n=30 / 180)$ and one relating to faculty engagement $(\mathrm{n}=12 / 180)$.

There is a strong link between students feeling that their instructors care about their success as engineers, and retention/student success [4][10]. The participants echoed the literature strongly; when instructors make them feel unwelcome and seem to not care about teaching their courses, it becomes a barrier to their success.

The participants made a case for placing strong teaching faculty in first year. Thirty participants, 7 first year students and 23 upper year students, suggested that the quality of instruction in their program acted as a barrier to their success and indicated that having stronger teaching in first year would have a positive effect. This included issues relating to unclear explanations of concepts, ambiguity in marking schemes, and a lack of resources available for them to teach themselves the concepts should the instructor not teach in a way that suits their learning style.

Along a similar vein, it seemed clear that students simply do not know how to learn on their own or where to find resources that are available (leading to them feeling as though those resources are not there). Engineers need to be resourceful and must be able to learn on their own; students would benefit from learning these skills in order to develop the lifelong learning aptitude that Engineers Canada has indicated as one of the 12 graduate attributes necessary for graduating engineers [1] .

\subsection{College Level}

College level factors are perhaps the most important factors to acknowledge as the literature suggests that college level factors can influence both instructor level factors and student level factors [4]. College level factors (particularly workload) were most cited by students as acting as barriers to their success, though it is impossible to separate college level themes entirely from one another or from other levels, because they are inextricably linked.

One college level barrier that emerged was the culture of undergraduate students $(\mathrm{n}=15 / 180)$. This included large class sizes that are intimidating to some students and that make them feel like a number, which makes it difficult for them to identify with their institution. In addition to this lack of belonging, students identified an unsettling trend of other students not wanting to excel in their program as being a barrier to their success. They felt that other students simply wanted to survive their undergraduate degree, emphasizing the "Cs get degrees" mentality. A general negative tone about first year engineering in and of itself can be damaging to first year students, making them feel that they are up against an impossible program.

When students believe that they are being set up to fail in their programs and/or that some instructors want them to fail (weed out culture), it lowers their self-efficacy and they are far more likely to drop out of university [9][10]. Additionally, if the impression that is being given to students is that engineering is a career that is unwelcoming and harsh, students who are statistically less likely to join the College are further dissuaded, such as female and minority students [6][8]. Though engineering colleges do not necessarily try to "weed-out" students, it is still some students' perception that a weed-out culture exists, which will have an effect on their success as a whole.

Another barrier that was strongly identified was the abstract nature of first year curriculum, and the perception that they cannot manage the heavy/rigorous curriculum of engineering while still learning the material well $(n=52 / 180)$. Students found it difficult to see the relevance of the curriculum to both their chosen discipline and to working in industry or research, which can be demotivating for students when they start off passionate about engineering. This is a problem that is noted in modern engineering education as being a cause for student attrition [2]. Students want to have the time to better understand the material, but feel that they have to pick and choose what they learn. This demanding workload again, disadvantages students with additional responsibilities, which could lead to the unfortunate loss of a competent and passionate engineer if no supports or flexible programing are in place.

\section{START}

Students were asked: "What could the College do/change to make first year more successful for engineering students?" There were 210 viable responses to this question, ranging from programming suggestions to events that the College could run. Many of their answers from the Start portion of the survey were essentially their solutions to the problems that they 
identified in the Stop portion of the survey. Because this is an ideation question, we received many ideas that were suggested by multiple respondents ( $n=5$ to $n=15)$. The top suggestions $(\mathrm{n}>25$ respondents $)$ revolved around instructors, college culture, and curriculum/workload, and will be discussed further.

\subsection{Instructor Resources}

The most prominent construct that emerged from the data revolved around improving quality of instruction and faculty engagement $(n=37 / 210)$. Colleges should consider having their best teaching faculty engaged in first year education, which in turn will benefit the entire institution by ensuring first year students are provided with a solid understanding of fundamental material before moving on to more difficult courses in upper years. However, learning is a shared responsibility between colleges and students, and the students will have to be willing to put in the effort as well. For example, many first year students choose not to read textbooks, yet are concerned about a lack of supporting resources.

There are many faculty members who are passionate and highly skilled at the research that they've built a career around, but these faculty members may have never received training in instruction. It may benefit engineering colleges to have instruction training available to faculty, to ensure that those faculty members that wish to improve their teaching, have the resources available to do so. Also, though many institutions have evaluations for their courses in place, students do not always feel that this feedback is used to improve their courses. Perhaps having compulsory evaluations (for both students and faculty), and ensuring that the feedback is addressed would be beneficial. The greater challenge is in incentivizing faculty to invest in teaching, given that many are evaluated mostly on their scholarship productivity.

\subsection{Improving College Culture}

Colleges who are welcoming students into first year who may be unprepared from high school would benefit from ensuring that students connect with one another. Approximately thirty students $(n=29 / 210)$ talked about peer networking, mentorship, and finding ways to help students connect and make friends as being integral to the success of engineering students (especially first years). Students want a positive atmosphere where they are encouraged, supported, and given the tools that they need to succeed. Students also felt that asking for student feedback more often helps to improve college culture and morale, because they then feel as though they are being heard.

Engineering students feel intense pressure to perform and suggested that it would benefit them in this fast paced environment to have free counselling and help available. It was also suggested that enhanced collegial engagement between faculty and students would benefit the student experience and improve their sense of belonging.

In contrast, colleges that promote "weed-out" culture have a higher chance of students dropping out, not because those students are academically incapable, but because students do not thrive in that type of environment, and instead find it demotivating [9][10]. The concept of "weeding students out" is pervasive, and students appear to be under the impression that engineering colleges try to weed them out rather than support them in their engineering career.

\subsection{Curriculum/Work Load}

The engineering curriculum is rigorous and heavy. Students felt that there was barely enough time to do the assignments each week, and that the heavy workload was not conducive to better learning $(n=27 / 210)$. They could not see the value in putting in that much effort. It was interesting throughout their answers that they were not asking for easier work, but rather to have enough time to better grasp the concepts and to have assignments that better aligned with exam assessments in terms of difficulty and course material.

\section{CONTINUE}

When asked "is there anything in your engineering degree so far that you feel is done well and helps students succeed?" overwhelmingly, nearly $50 \%(\mathrm{n}=103 / 221)$ of students responded positively to tutorials and help sessions. This suggests that it is worth the time/effort for colleges to invest in academic student support services.

The U of S College of Engineering implemented a new initiative this year called facilitated help sessions that first year students mentioned specifically as something that the College should continue $(n=53 / 221)$. In these help sessions, students are invited to spend 2-3 hours doing homework and/or studying any first year engineering 
subject, and are assisted by a peer mentor (teaching assistant/facilitator) when they have questions. There is one facilitator available for each first year engineering course, giving students access to immediate help and feedback regardless of what they are working on.

Instructors were listed as a positive factor in student success $(n=30 / 221)$, while poor instruction was listed as a barrier to student success. This suggests that students feel strongly that instructors have an impact on their success in engineering programs. If instruction has such a strong impact on student success, it is yet another reason why colleges should ensure that students have the highest quality teaching possible in first year, when they are most at risk to drop out of the college. It is also encouraging to know that colleges can make a significant difference in their students' learning outcomes and retention.

\section{LIMITATIONS}

The Stop-Start-Continue method (used as a framework) was a useful tool that induced constructive qualitative feedback. However, this data was generated by 365 students (a $21.5 \%$ response rate). Are the perceived barriers identified by these students that are shaped by their individual experience, the same as objective reality? We also cannot say if the barriers identified are from students who take responsibility for their own learning or not, and there is a question as to whether or not undergraduate students have enough context to say what the barriers are to their success i.e. it is sometimes easier to see this in hindsight.

It should be noted that students, in particularly the first two years, receive instruction from other colleges on campus and responses particular to the College were not separated from other colleges on campus.

Another limitation of this paper is that it does not discuss the correlation between a student's answers and their academic performance. The distribution of total degree average for the survey respondent population is slightly negatively skewed (a higher median average than the student population as a whole), but student responses were not broken down by total degree average. This data has also not yet been correlated with student motivation, specific disciplines, gender, or other variables that exist in quantitative data set, as this is the next step of this study.

\section{DISCUSSION/CONCLUSION}

This paper has shown themes that emerged from over six hundred qualitative responses, relating to three distinct questions. It is difficult to do a thematic analysis of this many participant answers without losing some of the individual voices of the participants. However, the high level take-always from this data set emerged clearly and naturally from the individuals who participated. This thematic analysis will eventually be analyzed along-side the quantitative survey data and other qualitative data sources, which gives us the potential to understand the factors that lead to students leaving the College and what factors impact student success (as defined by higher sessional weighted averages, retention, and graduation rates).

Though it is unlikely that engineering colleges can have an impact on high school curriculum, students identified that (some) high schools are not adequately preparing them for the difficulty and rigor of engineering. Additionally, when students fail to see the relevance of the first year workload to their career or upper year classes, they find it difficult to stay engaged with the curriculum [2].

When combing through the data, there was a sense that it was the shock of the workload and the abstract nature of the material that made it difficult to transition from high school to first year engineering. It may be then, that the problem is not necessarily the heavy workload, but the inability of first year students to see how the engineering curriculum relates to upper year courses/their engineering careers, as well as the shock of transitioning from being a top student in their high school to struggling in first year engineering. To alleviate this shock, colleges should ensure that the workload and difficulty of engineering curriculum are made clear to first year students, and that those students with lesser academic preparation are given the tools and resources that they need to catch up to their more prepared peers.

This opens up a discussion on what is and is not a college's responsibility in regards to student outcomes. It is easy to say that every student needs to rise to the same bar, but engineering colleges must realize that not every student has been given the same opportunities in life, and that some students have farther to go to get to that bar than others. That is not to say that engineering colleges should make their programs easier or lower that bar, but rather that they should ensure that supports are in place 
that allow the students who are accepted into our colleges and want to do well, succeed.

Whether or not first year engineering should weed out students is a polarizing issue in the engineering education world; some believe that it is beneficial to have a year to weed students out, if engineering is "not right for them". Some disagree. But when you look at the data and the literature, "weed-out mentality" is damaging to the overall morale of the student body, and does not ensure that the "cream of the crop" are the ones who stay. In reality, some of the students who leave engineering colleges could be great engineers, but leave as a result of the "weed-out" atmosphere.

If engineering colleges offer greater flexibility in their programs, enabling students to find a better balance with their personal lives, it may open up the engineering profession to a wider range of students, especially those with families and those that need to have a job outside of university classes.

Students also tend to achieve better learning outcomes in courses where the instructor is engaged and when the students feel that their instructors want them to succeed [7][10]. Engineering colleges would benefit from choosing first year professors who enjoy teaching and have a track record of explaining concepts clearly (via student feedback) even though there may be difficulty in doing this, since many first year engineering programs are not taught solely by engineering faculty.

The various factors that were identified by participants as barriers to their success are important to understand as part of a larger network of issues that can, for the most part, be affected by college level programming and culture [4][9]. Engineering college leaders have an opportunity to make a measureable difference in student outcomes by placing emphasis on the importance of student learning as an investment in the future of the engineering profession. Creating a culture where teaching is rewarded and where students are made to feel supported and encouraged would be greatly beneficial to engineering colleges, individual students, and as a result, the engineering profession.

\section{Acknowledgements}

We would like to acknowledge the Gwenna Moss Centre for Teaching Effectiveness and the University of Saskatchewan for financially supporting this research project and supporting the College of Engineering in its efforts to understand student success and retention. We would also like to thank the students for responding thoughtfully to our questions, and to the College of Engineering at the University of Saskatchewan for their commitment to quality education.

\section{References}

[1] Engineers Canada, "2015 Accreditation Criteria and Procedures,” Ottawa, 2015.

[2] J. E. Froyd and M. W. Ohland, "Integrated engineering curricula," Journal of Engineering Education, vol. 94, no. 1, pp. 147-164, 2005.

[3] A. Hoon, E. Oliver, K. Szpakowska, and P. Newton, "Use of the 'Stop, Start, Continue' method is associated with the production of constructive qualitative feedback by students in higher education," Assessment \& Evaluation in Higher Education, vol. 40, no. 5, pp. 755-767, 2015.

[4] E. Kuley, T. Fonstad, and S. Maw, "Engineering Student Retention and Attrition Literature Review," in Proceedings of the Canadian Engineering Education Association, 2015.

[5] R. J. Marzano, What Works in Schools: Translating Research into Action. Alexandria, VA: Association for Supervision \& Curriculum Development, 2003.

[6] M. Ong, C. Wright, L. L. Espinosa, and G. Orfield, "Inside the double bind: a synthesis of empirical research on undergraduate and graduate women of color in science, technology, engineering, and mathematics," Harvard Educational Review, vol. 81, no. 2, pp. 172-209, 2011.

[7] B. Christe, "The Importance of Faculty-Student Connections in STEM Disciplines: A Literature Review," Journal of STEM Education : Innovations and Research, vol. 14, no. 3, pp. 22-26, 2013.

[8] R. T. Palmer, D. C. Maramba, and E. T. I. Dancy, “A Qualitative Investigation of Factors Promoting the Retention and Persistence of Students of Color in STEM," Journal of Negro Education, 2011.

[9] R. Suresh, "The Relationship Between Barrier Courses and Persistence in Engineering," Journal of College Student Retention, vol. 8, no. 2, pp. 215-239, 2007.

[10] C. M. Vogt, "Faculty as a Critical Juncture in Student Retention and Performance in Engineering Programs," Journal of Engineering Education, vol. 97, no. 1, pp. 27-36, Jan. 2008. 